\title{
EVALUACIÓN FISICOQUÍMICA Y BROMATOLÓGICA DE CUATRO VARIEDADES NATIVAS DE PAPA (Solanum SPP.)
}

\author{
Physical chemistry and bromatological evaluation of four varieties of potato (Solamun spp.)
}

\author{
Antonio Obregón ${ }^{1}$, Ritva Repo ${ }^{2}$
}

${ }^{1}$ Facultad de Farmacia y Bioquímica, Universidad Nacional Mayor de San Marcos. ${ }^{2}$ Facultad de Industrias Alimentarias, Universidad Nacional Agraria La Molina

\section{RESUMEN}

Se evaluaron cuatro variedades nativas de papa: amarilla runtus (Solanum goniocalyx), huayro (Solanum chaucha), peruanita (Solanum goniocalyx Juz. \& Bukasov) y huamantanga (Solanum tuberosum andigena), procedentes de la provincia de Huancayo, región Junín. Estas variedades presentaron diámetro promedio mayor a $30 \mathrm{~mm}$, forma redondeada y alargada, piel amarilla y rojiza. El contenido de materia seca fue de 22,98 a 31,80\%, presentando relación directa con la gravedad específica y el contenido de almidón, de 17,50 a $26,20 \%$. Los altos contenidos de almidón y materia seca encontrados las clasifican como tubérculos de alta calidad culinaria, siendo adaptables para la fabricación de productos deshidratados o fritos. Las muestras secas, en gramos por ciento, presentaron: proteínas totales_6,75 a 10,54; extracto etéreo o,22 a 0,35; ceniza 2,23 a 3,79; fibra cruda 1,48 a 2,33; carbohidratos 84,01 a 87,89; azúcares reductores 1,50 a 1,80; acidez total o,13 a 0,28; valor calórico 380,20 a 382,86 Kcal. El contenido de vitamina $C$ fue de 7,85 a 16,19 mg\%. El pH varió de 6,30 a 6,90.

Palabras clave: Solanum spp., tubérculo, evaluación químico bromatológica.

\begin{abstract}
Were evaluated four native varieties of potato: yellow runtus (Solanum goniocalyx), huayro (Solanum chaucha), peruanita (Solanum goniocalyx Juz. \& Bukasov) and huamantanga (Solanum tuberosum andigena), from the peruvian highlands, province of Huancayo, department of Junin. These potato varieties had an average diameter greater than $30 \mathrm{~mm}$, with rounded and elongated shapes, having yellow and reddish skin. The dry matter content was 22,98 to 31,80\%, showing a direct relationship with the specific gravity and the starch content (17,50 to $26,20 \%)$. The high content of starch and dry matter found, classified them as high quality tubers culinary, being suitable for the manufacture of dried products fried products. The dry samples, in grams percent, showed: total protein 6,75 to 10,54 ; ethereal extract 0,22 to 0,35 ; ash 2,23 to 3,79; raw fiber from 1,48 to 2,33; carbohydrates from 84,01 to 87,89; reducing sugars from 1,50 to 1,80; total acidity from o,13 to 0,28 ; caloric value from 380,20 to $382,86 \mathrm{Kcal}$. Vitamin C content was 7,85 to $16,19 \mathrm{mg} \%$. pH varied from 6,30 to 6,90.
\end{abstract}

Keywords: Solanum spp, tuber, chemistry and bromatological evaluation.

\section{INTRODUCCIÓN}

a papa (Solanum tuberosum), producto originario de los Andes peruanos y uno de los principales cultivos alimenticios del mundo, siendo una de las plantas de mayor diversidad genética. Existen ocho especies cultivadas de papas originarias de los andes y 200 especies silvestres. Sin embargo hasta la actualidad, la evolución del cultivo ha favorecido a Solanum tuberosum subespecie andígena, a partir de la cual se han desarrollado la mayoría de las variedades comerciales conocidas. Las otras siete especies cultivadas en la zona andina son menos desarrolladas y corren riesgo de extinción y pérdida del material genético ${ }^{(1)}$.

La biodiversidad de estas especies presenta un desarrollo desigual con marcadas diferencias regionales; algunas son conocidas en el ámbito nacional y su consumo es difundido; otras solo tienen presencia regional; mientras que la mayor parte son desconocidas quedando expuestas a la desaparición de sus genomas. Las papas nativas, son el resultado de un proceso de domesticación, selección y conservación ancestral, herencia de los antiguos habitantes de nuestros Andes. Estas papas son altamente valoradas por científicos y agricultores andinos, tanto por sus propiedades organolépticas (sabor, textura, color, forma) como agrícolas. A diferencia de las papas mejoradas, las variedades nativas, tienen un mayor contenido de sólidos por lo que son más nutritivas y dan un sabor especial a los preparados ${ }^{(1,2)}$.

Las papas nativas tienen buen potencial para el desarrollo de nuevos productos, por lo que es necesario profundizar los estos cultivos, altamente promisorios y de trascendental importancia para la 
alimentación y desarrollo agroindustrial de nuestro país. Es así que el objetivo del presente trabajo de investigación fue caracterizar, fisicoquímica y bromatológicamente, cuatrovariedades de papa oriundas delosandes peruanos.

\section{MATERIALES Y MÉTODOS}

Materia prima. Se trabajó con cuatro variedades de papas nativas: amarilla runtus (Solanum goniocalyx), huayro (Solanum chaucha), peruanita (Solanum goniocalyx Juz. \& Bukasov) y huamantanga (Solanum tuberosum andígena). Los tubérculos provinieron de la zona central de la sierra peruana, Huancayo-Junín (3000-400o msnm).

Preparación de las muestras. Se procedió a preparar las muestras, realizando inicialmente la selección de las mismas, para luego ser lavadas, peladas y ralladas para su homogeneización. Se estabilizaron y conservaron en frascos ámbar herméticamente cerrados para los análisis respectivos.

Determinaciones analíticas. El tamaño se determinó por medio de la medición del diámetro y la altura, en una muestra de 10 tubérculos tomada al azar por cada variedad. Para la determinación de la gravedad específica, se utilizó el método de la doble pesada, el cual consiste en pesar los tubérculos en el aire y luego sumergirlos en agua. El contenido de agua, proteínas totales, extracto etéreo, cenizas y fibra cruda fueron determinados utilizando los métodos de la AOAC. El factor utilizado para calcular la proteína fue de 6,25. Los carbohidratos fueron obtenidos por diferencia, es decir sustrayendo de 100 la suma de agua. La vitamina $C$ se determinó por el método de titulación con 2,6-diclorofenolindofenol. Las determinaciones de almidón, azúcares reductores totales, $\mathrm{pH}$ y acidez total se realizaron utilizando los métodos de la AOAC ${ }^{(3)}$.

\section{RESULTADOS}

En la tabla 1 se muestran las características morfológicas de los tubérculos evaluados y en la tabla 2 se presentan los resultados de la evaluación fisicoquímica y bromatológica.

\section{DISCUSIÓN}

Las variedades de papa estudiadas, presentaron un diámetro promedio mayor de $30 \mathrm{~mm}$, mostrando formas redondeadas, las variedades peruanita y amarilla runtus, y formas alargadas las variedades huamantanga y huayro. De acuerdo con Arispe ${ }^{(4)}$, la clasificación de los tubérculos, evaluados en función al tamaño, correspondió a una calidad de papa de tercera. Cabe indicar que Monteros y col (2), señalan que algunas de las desventajas que presentan las variedades nativas de papa son los bajos rendimientos, tamaño pequeño y poca uniformidad; teniendo como ventajas su buen sabor y textura, así como su alta variabilidad en formas y colores que las hacen atractivas para el consumidor.

En cuanto a la gravedad específica, las variedades amarilla runtus y peruanita (1,11 y 1,15; respectivamente) mostraron valores superiores respecto a las variedades huayro y huamantanga (1,08 y 1,09; respectivamente). El contenido de sólidos totales o materia seca de los tubérculos evaluados (22,98 a 31,80\%) se encuentran dentro del rango reportado por Lisinska y Leszcynski ${ }^{(5)}$ y Singh y Lovedeep ${ }^{(6)}$, quienes señalan que dicho contenido guarda una relación directa con su gravedad específica, en rangos de 1,0485 a 1,151 g/ $\mathrm{cm}^{3}$, lo cual fue corroborado en ésta investigación.

Burton (7) clasifica a los tubérculos, en base a su contenido de materia seca, en nivel elevado si es más de $23 \%$, mediano de 21 a $23 \%$ y bajo si es menor a $21 \%$, por lo que las variedades nativas evaluadas, se encontrarían entre los niveles mediano y elevado.

Las muestras estudiadas presentaron altos contenidos de almidón y materia seca por lo que ostentan alta calidad culinaria, siendo adaptables para la fabricación de productos deshidratados y productos fritos ${ }^{(6,7,9)}$.

El contenido de proteína, extracto etéreo, ceniza, fibra, carbohidratos y valor energético de las variedades de papa se encontraron dentro del rango reportado por Ramos ${ }^{(8)}$, Lisinska y Leszcynski ${ }^{(5)}$, Singh y Lovedeep ${ }^{(6)}$ y Vinatea ${ }^{(9)}$.

Las variedades amarilla runtus y peruanita reportaron valores más altos en contenido de vitamina C, 16,19 y 10,81 mg\%; respectivamente, en comparación a los cultivares huayro y humantanga $(8,90$ y $7,85 \mathrm{mg} \%$, respectivamente), lo cual concuerda con lo señalado por

Tabla 1. Características morfológicas de variedades nativas de papa.

\begin{tabular}{lcccc}
\hline \multicolumn{1}{c}{ Características } & Peruanita & $\begin{array}{c}\text { Amarilla } \\
\text { runtus }\end{array}$ & Huayro & Huamantanga \\
\hline Peso promedio (g) & 58,40 & 55,30 & 67,40 & 65,60 \\
Longitud promedio (mm) & 42,00 & 40,50 & 61,20 & 85,00 \\
Diámetro promedio (mm) & 35,50 & 33,30 & 35,10 & 30,30 \\
Forma & Redondeada & Redondeada & Alargada & Alargada \\
Color de piel & Rojo con & Amarillo & Rojiza & Crema \\
& amarillo & cremoso & Blanco con & Blanco \\
Color de la pulpa & Amarillo & Amarillo & $\begin{array}{c}\text { pigmentaciones } \\
\text { rojizas }\end{array}$ & amarillento \\
\hline
\end{tabular}


Tabla 2. Composición fisicoquímica y bromatológica de variedades nativas de papa.

\begin{tabular}{|c|c|c|c|c|c|c|c|c|}
\hline & \multicolumn{2}{|c|}{ Peruanita } & \multicolumn{2}{|c|}{ Amarilla runtus } & \multicolumn{2}{|c|}{ Huayro } & \multicolumn{2}{|c|}{ Huamantanga } \\
\hline & Fresca & Seca & Fresca & Seca & Fresca & Seca & Fresca & Seca \\
\hline & \multicolumn{8}{|c|}{$(\%)$} \\
\hline Gravedad específica & 1,15 & & 1,11 & & 1,09 & & 1,08 & \\
\hline Sólidos totales & 27,90 & 100,00 & 31,80 & 100,00 & 24,60 & 100,00 & 22,98 & 100,00 \\
\hline Agua & 72,10 & 0,00 & 68,20 & 0,00 & 75,40 & 0,00 & 77,02 & 0,00 \\
\hline Proteínas totales $(*)$ & 2,94 & 10,54 & 2,33 & 7,33 & 1,66 & 6,75 & 2,30 & 10,01 \\
\hline Extracto etéreo & 0,07 & 0,25 & 0,07 & 0,22 & 0,09 & 0,37 & 0,08 & 0,35 \\
\hline Cenizas & 0,98 & 3,51 & 0,71 & 2,23 & 0,89 & 3,62 & 0,87 & 3,79 \\
\hline Fibra cruda & 0,47 & 1,68 & 0,74 & 2,33 & 0,44 & 1,79 & 0,34 & 1,48 \\
\hline Carbohidratos & 23,44 & 84,01 & 27,95 & 87,89 & 21,52 & 87,48 & 19,39 & 84,38 \\
\hline Almidón & 23,01 & 82,47 & 26,20 & 82,39 & 20,02 & 81,38 & 17,50 & 76,15 \\
\hline Azúcares reductores & 0,50 & 1,80 & 0,51 & 1,60 & 0,37 & 1,50 & 0,38 & 1,65 \\
\hline Vitamina $C\left({ }^{* *}\right)$ & 10,81 & 38,75 & 16,19 & 50,91 & 8,90 & 36,18 & 7,85 & 34,16 \\
\hline Acidez & 0,06 & 0,21 & 0,09 & 0,28 & 0,03 & 0,13 & 0,05 & 0,22 \\
\hline $\mathrm{pH}$ & 6,90 & & 6,60 & & 6,30 & & 6,70 & \\
\hline Valor calórico $(* * *)$ & 106,15 & 380,47 & 121,75 & 382,86 & 93,53 & 380,20 & 87,48 & 380,68 \\
\hline
\end{tabular}

* Factor de proteína $=6,25$; ** Valor expresado en $\mathrm{mg} \%$; ${ }^{* *}$ Valor expresado en Kilocalorías proteínas totales de 6,75 a 10,54; extracto etéreo de 0,22 a 0,35 ; cenizas de 2,23 a 3,79; fibra cruda de 1,48 a 2,33; carbohidratos de 84,01 a 87,89 ; azúcares reductores de 1,50 a 1,80 ; acidez total de 0,13 a 0,28 ; valor calórico de 380,20 a $382,86 \mathrm{kcal}$. El contenido de vitamina $\mathrm{C}$ fue de 7,85 a $16,19 \mathrm{mg} \%$. El pH varió de 6,30 a 6,90 .

\section{REFERENCIAS BIBLIOGRÁFICAS}

Burton ${ }^{(7)}$, quien señala que los tubérculos que presentan un color amarillo más intenso contienen probablemente más vitamina $C$. Cabe indicar que Ramos ${ }^{(8)}$ y Vinatea ${ }^{(9)}$, señalan que el contenido de vitamina $C$ en los tubérculos es un factor que depende de la variedad, manejo y procedencia de la materia prima.

El contenido de azúcares reductores (o,37 a $0,50 \%)$ de las variedades de papa estudiadas se encuentra dentro del rango establecido por Lisinska y Leszczynski ${ }^{(5)}$, Singh y Lovedeep ${ }^{(6)}$ y Vinatea ${ }^{(9)}$. Este contenido, en la papa, es variable y está influenciado por la variedad, localización, condiciones de cultivo y almacenamiento. Los azúcares reductores tienen vital importancia en el procesamiento y almacenamiento de productos elaborados, pues éstos dan lugar a reacciones químicas complejas que alteran la calidad del producto produciendo coloraciones y sabores indeseables ${ }^{(8,9)}$.

LosvaloresdepHyacidez deloscultivaresestudiados difieren de los reportados por Lisinska y Leszczynski ${ }^{(5)}$ y Singh y Lovedeep ${ }^{(6)}$, al presentar valores de $\mathrm{pH}(6,30$ a $6,90)$ más altos y por ende valores de acidez (o,03 a o,09) más bajos; esto es debido a que el contenido de ácidos orgánicos de la papa varía según su estado de madurez, aquellos tubérculos que son cosechados tempranamente presentan valores de acidez más bajos ${ }^{(6,7)}$.

\section{CONCLUSIONES}

Las variedades nativas de papa presentaron un diámetro promedio mayor a $30 \mathrm{~mm}$ mostrando formas redondeadas las variedades peruanita y amarilla runtus y las variedades huamantanga y huayro, formas alragadas. El contenido de materia seca fue de 22,98 a $31,80 \%$, presentando relación directa con la gravedad específica y el contenido dealmidón (de 17,50 a 26,20\%). Las muestras secas, en gramos por ciento presentaron:
1. Álvarez M, Repo R. Desarrollo de productos de papas nativas. Centro Internacional de la Papa. Lima, 1999.

2. Monteros C, Cuesta X, Jiménez J, López G. Las papas nativas en el Ecuador. INIAP Archivo Histórico. Quito, 2005.

3. AOAC. Official Methods of Analysis of the Association of Official Analytical Chemist. $15^{\text {th }}$ ed. Gaithersburg, Maryland, 2005.

4. Arispe M. Evaluación de los parámetros tecnológicos en el procesamiento de papa seca utilizando diversas variedades de papa. [Tesis para optar el título de Ingeniero en Industrias Alimentarias] Universidad Nacional Agraria La Molina. Lima, 1986.

5. Lisinska G, Leszczynski W. Potato scienceand technology. Elsevier Applied Science Publishers. London, 1989.

6. Singh J, Lovedeep K. Advances in potato chemistry and technology. $1^{\text {st }}$ ed. Academic Press. 2009.

7. Burton W. The Potato. Longman Scientific \& Technical. Essex, 1989.

8. Ramos V. Caracterización y selección de papas cultivables en el Perú para la elaboración de hojuelas (chips) y tiras (french fries potatoes) fritas. [Tesis para optar el título de Ingeniero en Industrias Alimentarias]. Universidad Nacional Agraria La Molina. Lima, 1992.

9. Vinatea P. Deshidratación de hojuelas de cuatro variedades de papas nativas (Solanum spp.). [Tesis para optar el título de Ingeniero en Industrias Alimentarias]. Universidad Nacional Agraria La Molina, Lima, 2010.

10. International Potato Center (CIP). Potato science for the poor: Challenges for the new millennium a working conference to celebrate the international year of the potato. Lima, 2008: 28.

\section{Correspondencia}

Nombre: $\quad$ Antonio José Obregón La Rosa

Dirección: Jr. Luis Pardo 1128, Lima 31.

E-mail: aobregonl@unmsm.edu.pe 